\title{
An experimental study on the effect of marine corrosion on frictional properties of sliding pairs of offshore isolated bridges
}

\author{
Guifeng Zhao ${ }^{1, a}$, Yuhong Ma ${ }^{2, b}$, Yanmin $\mathrm{Li}^{2, \mathrm{c}}$,Liangjian ${ }^{1, \mathrm{~d}}$, Kangkang Wang \\ ${ }^{2, e}$, and Fulin Zhou ${ }^{2, f}$ \\ ${ }^{1}$ School of Civil Engineering, Guangzhou University, Guangzhou 510006, China \\ ${ }^{2}$ Earthquake Engineering Research \& Test Center, Key Laboratory of Seismic Control and \\ Structural Safety, Guangzhou University, Guangzhou 510405, China \\ a1766674920@qq.com, b849502749@qq.com, c1015922630@qq.com, d276133847@qq.com, \\ e983719042@qq.com, 'tzhoufl@cae.cn
}

\begin{abstract}
Keywords: offshore isolated bridges; marine corrosion; sliding pairs; periodic-salt-spray test; wet-and-dry cycle test; performance deterioration law.

Abstract. In this study, a series of corrosion tests are performed on 12 sliding pairs under complex marine environment and earthquake. Periodic-salt-spray accelerated corrosion test and wet-and-dry-cycle accelerated corrosion test are used to simulate the splash zone and atmospheric zone for an sliding pair. This study analyzes various factors that influence corrosion and determines corresponding accelerating ratio of the factors in the accelerated test. An experimental plan is designed, and the major phenomena at different stages of corrosion are discussed. Relationships are obtained for the deterioration of the static and dynamic friction coefficients with corrosion time for the sliding pairs. The results show that the friction coefficients of the sliding pairs on both splash zone and atmospheric zone show a similar periodic curve. Friction coefficients are increased firstly, then decreased, next increased, and finally decreased. After 60 years of simulated marine corrosion, the static friction coefficients are increased but the dynamic friction coefficients are decreased. The relationships obtained for the deterioration of the friction coefficients may provide a basis to investigate the variation in the performance of a friction pendulum bearing and the performance evaluation of offshore isolated bridges in their service lives.
\end{abstract}

\section{Introduction}

In recent years, seismic isolation technology has been used extensively in offshore bridges in China to improve structural seismic performance of bridges. In particular, friction pendulum bearings are widely used because of their excellent self-recovery ability and anti-torsion ability. The friction pendulum bearings installed between a deck and a pier play an important role on earthquake resistance. These bearings are subjected to the effect of temperature, humidity, acid rain, salt fog and other complex environmental factors during the life span of the bridge, and with time, they may deteriorate and even fail. However, most studies are focused on the mechanical properties of the friction pendulum bearings and the seismic performance of the bridge structures [1-6]. Even though some studies exist specifically on the composition of the bearing material such as Teflon (PTFE) plate and stainless steel plate, performance deterioration of friction pendulum bearings subjected to long-term exposure under complex marine environment is not adequately understood. PTFE has superior stability and corrosion resistance [7], so in this paper only the corrosion resistance of the stainless steel is considered. The minimum chromium content of stainless steel is $10.5 \%$ and the maximum carbon content is $1.2 \%$. Stainless steel has the characteristics of corrosion resistance [8]. However, the stainlessness of stainless steel is a relative measure. Corrosion can still occur in stainless steel in some cases [9].

Fifty kinds of metallic materials have been studied for corrosion exposure in four different sea areas in China for sixteen years since 1983 [10]. Accordingly, huge database and various relationships have been obtained for different characteristics of seawater corrosion of metallic materials for long duration [10]. You et al. [11] reported that corrosion damage of stainless steel is caused by pitting 
corrosion and crevice corrosion. They also argued that different types of stainless steel in different marine areas have marked differences in corrosion resistance. Based on a [12]-year exposure under atmospheric condition, Liang et al. [12] reported that corrosion of stainless steel is influenced the most by $\mathrm{Cl}^{-}$among various environmental factors affecting corrosion. The study of Liang [12] showed that humid and hot environment and $\mathrm{Cl}^{-}$result in higher corrosion rates. Based on a test in simulated ocean atmosphere, Fan et al. [13] found that the rate of corrosion of stainless steel is increased with an increase in $\mathrm{Cl}^{-}$. In Su's paper [14] that focused on the corrosion in submerged zone, the corrosion of steel in marine environment was discussed from two aspects, namely, material property and marine environment. The factors that result in the corrosion of stainless steel in circulating water have been analyzed by Pan et al. [15] Moreover, the mechanism and forms of the stainless steel corrosion caused by $\mathrm{Cl}^{-}$was discussed in their paper. The effect of salinity, flow rate, $\mathrm{pH}$ value and temperature on the corrosion rate of AISI 316 stainless steel was studied by Atashin S. et al. [16] The corrosion laws of stainless steel at different $\mathrm{pH}$ values under an environment of 3.5\% (mass fraction) $\mathrm{NaCl}$ solution in $27{ }^{\circ} \mathrm{C}$ were obtained by Lothongkum G. et al. [17]. Ali et al. [18] performed a high temperature corrosion test of stainless steel for $5000 \mathrm{~h}$ to obtain the corrosion rate of stainless steel. Accelerated corrosion of $316 \mathrm{~L}$ stainless steel in artificial seawater at $50{ }^{\circ} \mathrm{C}$ was performed by Cai et al. [19] to investigate the corrosion characteristics of stainless steel. Dolce, M. et al. [20] summarized the results of experimental investigation on steel-PTFE interfaces, evaluated the effects of sliding velocity, contact pressure, air temperature and state of lubrication on the mechanical behavior of steel-PTFE sliding bearings.

According to the above analysis, most of current research is focused on corrosion rate and corrosion characteristics of stainless steel. However, the variation in static and dynamic friction coefficients of friction pendulum bearing has not been studied yet. Therefore, it is important to investigate the performance variation of friction pendulum bearing during its service life for the performance evaluation of the life of offshore isolated bridges.

A sliding pair is composed of high-friction material and a mirror face plate. In typical equations of a friction pendulum, the horizontal yield stiffness is related only to the vertical force and the radius of curvature. Therefore, in order to simplify the test conditions and focus on the variation in friction coefficients with marine environment, sliding pairs in this paper are produced with the same material as friction pendulum bearings. A series of tests with identical test environment are performed on the sliding pairs and the friction pendulum bearings. It is mentioned that the bearing wear caused by normal usage of the bridge and variation in ambient temperature during the 60 year service life of the bridge was not taken into account in this study.

\section{Specimen and test plan for sliding pairs}

Generally, two methods are used to test the performance deterioration of friction pendulum bearing. One is the real-sea test in which bearing is put in the real ocean environment for the study. It may take several years and consume a lot of resources, and hence, it is rarely used. The other is the artificial accelerated test in which the performance deterioration of friction pendulum bearing is accelerated by intensifying some environmental factors so as to simulate the real ocean environment and to shorten the test duration. It is the commonly used test method at present. This accelerated method can be further classified as, (i) hot-humid and full-dip accelerated corrosion test, (ii) periodic-salt-spray accelerated corrosion test, and (iii) wet-and-dry-cycle accelerated corrosion test.

Most of the seismic isolation bearings in offshore bridge are in the marine atmospheric zone. However, bearings in non-navigable parts and bearings at both ends of a bridge approach may be in the splash zone due to the low height of bridge piers. Hence, the situations of sliding pairs in atmospheric zone and splash zone were mainly considered in this paper. Considering the operability of an accelerated test in the laboratory, periodic-salt-spray accelerated corrosion test and wet-and-dry-cycle accelerated corrosion test were performed. They were used, respectively, to simulate the situations that the bearing is in (a) moist splash zone of marine atmosphere and (b) 
alternate wet and dry atmospheric zone for a long time.

A sliding pair was made of a Teflon plate and a stainless steel plate. The diameter and thickness of the Teflon plate were, respectively, $100 \mathrm{~mm}$ and $7 \mathrm{~mm}$. The length, width and thickness of the stainless steel plate were, respectively, $360 \mathrm{~mm}, 210 \mathrm{~mm}$, and $2 \mathrm{~mm}$ as shown in Fig. 1. Twelve sliding pairs were used in this study.

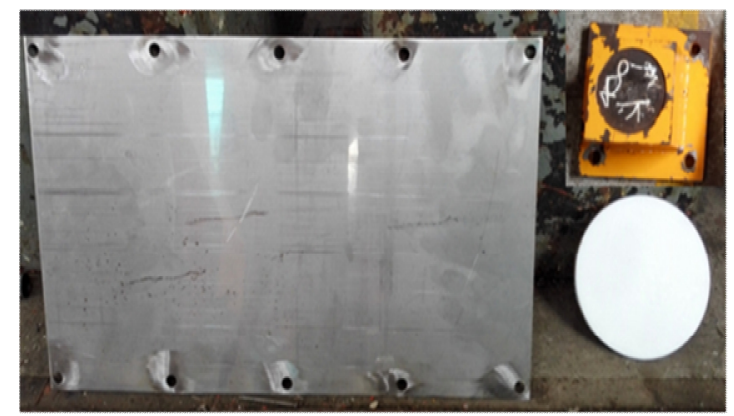

Fig. 1 Stainless steel plate, Teflon plate and fixture tools of sliding pairs

Influencing factors for corrosion and determination of accelerating rate

The rate of corrosion of metal is related mainly to external environment when the metal is in a certain state. Therefore, the corrosion of metal can be predicted by measuring environmental parameters. Marine environmental factors that affect the corrosion of stainless steel mainly include temperature, humidity, salt concentration, $\mathrm{pH}$ value, time ratio of wet-and-dry-cycle test, spray pattern of periodic-salt-spray test, and displaying angle of the sample. In order to obtain the variation in the performance of the sliding pairs with time by conducting the artificial accelerated corrosion test, the accelerating rate for each corrosion factor of the test was determined at first.

(1) Rate of acceleration for salt concentration: Salinity is defined as the total grams of dissolved solid salts in $100 \mathrm{~g}$ sea water. Considering the salt content composition table of seawater in an ocean, the salinity table of seawater in various sea areas, and the specific environmental parameters of four seawater corrosion stations in China, the mean salinity of seawater in China was considered as 3.5\% [21]. However, a relationship between the loss of metal and the concentration of salt solution [22] shows that the rate of corrosion of metal is the highest when the concentration of salt solution is approximately $5 \%$. Salt solution with too high concentration is likely to cause the blockage of salt spray nozzle but salt solution with too low concentration leads to decrease reduction in corrosion. Hence, the salt concentration in the accelerated test was taken as $(5 \pm 1) \%$ and the rate of acceleration as approximately 1.1 times.

(2) Rate of acceleration for temperature: In order to reasonably consider the actual environmental temperature of an isolated friction pendulum bearing (or a sliding pair) in an offshore isolated bridge, the temperature of ten coastal cities in China was analyzed to obtain monthly mean maximum temperature chart, monthly mean minimum temperature chart and annual mean temperature chart [23]. According to these charts, the actual environmental temperature of the sliding pair was taken as $20^{\circ} \mathrm{C}$.

In general, the temperature in the salt-spray accelerated test is taken as $35^{\circ} \mathrm{C}$ that is equal to the highest average temperature in summer in many countries. According to the Van't Hof rules [24], the effect of temperature on concentration can be neglected, however the rate of reaction increases with an increase in temperature in most chemical reactions. For every $10{ }^{\circ} \mathrm{C}$ increase in temperature, the rate of reaction is increased by 2 4 times. Since the test temperature in this study was $15{ }^{\circ} \mathrm{C}$ higher than the actual environmental temperature, the rate of acceleration due to temperature was taken as 3.5 .

(3) Rate of acceleration for $\mathrm{pH}$ value: The $\mathrm{pH}$ value of seawater is quite stable because the carbonate and other salts in the sea have a strong buffering effect. The $\mathrm{pH}$ value of seawater is between 8 and 8.2 [21], [25]. The corrosion rate of cadmium, iron and other metal materials is increased with a decrease in the $\mathrm{pH}$ value of solution [22]. In order to enhance the reproducibility of the test and the accuracy of the results, the $\mathrm{pH}$ value of the periodic-salt-spray test was taken as 
6.5 7.2. The rate of corrosion of the test was approximately 1.2 times of the rate of corrosion in an actual marine environment. Thus, the rate of acceleration for the $\mathrm{pH}$ value was taken as 1.2.

(4) Rate of acceleration for the deposition rate of salt spray (relative humidity): Relative humidity is changed greatly with the variation in region and season. High relative humidity contributes to the formation of a liquid film on the surface of a metal in air [26]. When the environmental temperature is $23{ }^{\circ} \mathrm{C}$, the average relative humidity of the atmosphere is usually taken as $50 \%$. The critical relative humidity for metal corrosion is approximately $70 \%$. When the relative humidity exceeds the critical relative humidity, salt deliquesces and forms conductive electrolyte. When the relative humidity is below the critical level, salt concentration is increased until crystalline salt precipitates out and the rate of corrosion is reduced accordingly.

The deposition rate of salt spray is defined as the amount of salt-spray deposition in unit area per unit time. Salt spray is made up of tiny droplets. These droplets are easily attached to the surface of the object, thus forming a moisture film or water film on the surface. Metal corrosion is caused by these films. Yang et al. [27] showed that the higher the content of salt spray in air and the greater the deposition rate of salt spray, the faster becomes the rate of corrosion. In the test, a steady stream of salt spray settled on the bearings because the relative humidity in the salt-spray test was greater than the critical humidity. Hence, the air in the test box was in the state of saturated humidity. According to the above analysis, the relative humidity of the air in the salt spray box was taken as $95 \%$ and the deposition rate of salt spray in the test was taken as $1 \sim 2 \mathrm{~mL} / 80 \mathrm{~cm} 2 \cdot \mathrm{h}$. According to the relationship between corrosion weight gain and relative humidity [28], as shown in Fig. 2, the corrosion weight gain of the test metal in 1 day in an atmosphere of $95 \%$ relative humidity is equivalent to the corrosion weight gain in 42.6 days in an atmosphere of $50 \%$ relative humidity. Therefore, the rate of acceleration for relative humidity was taken as 42.6 .

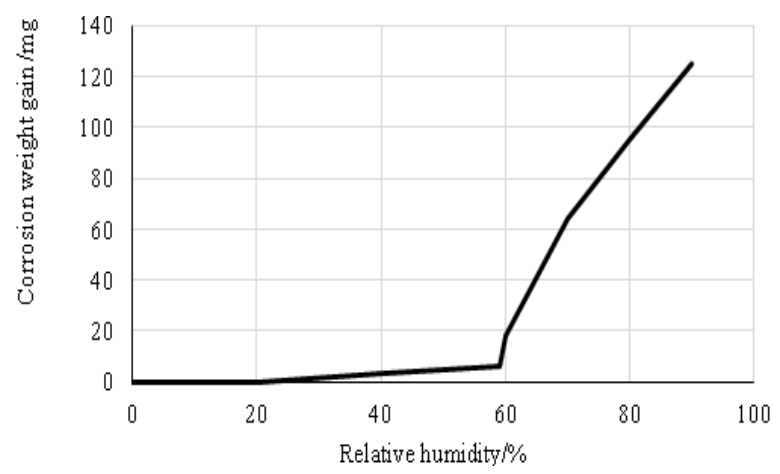

Fig. 2 Relationship between corrosion weight gain and relative humidity

(5) Periodic-spray and wet-and-dry-cycle mode: Due to the influence of weather factors such as relative humidity, temperature, wind speed, light, and condensation, water film that causes electrochemical corrosion on metal surface does not exist for a long time. In other words, corrosion is not a continuous process, but a wet-and-dry cycle. Therefore, an experimental device is required to simulate the visible water film formed in natural environmental condition and the adsorbed water film formed under high relative humidity. In addition, it is also required that the experimental device should simulate the process of hot air drying or light drying in which the water film on the surface of the sample is changed from thick to thin or from wet to dry. Based on the study of marine environment and the statistics of ten major coastal cities, the ratio of sunny days to rain days was reported as 2:1 [21]. Hence, in this study, an intermittent pattern was selected for the spray pattern with the period taken as 24 hours. The wetting time was taken as 8 hours and the drying time was taken as 16 hours.

(6) Place angle of the sample: The sliding pairs were placed horizontally because the sample was required to simulate the normal use condition of a bearing. The salt spray dropped vertically on the sliding pairs and most of the corrosion occurred on the side that faced to the salt spray in the sliding pairs.

(7) Duration of accelerated corrosion test: According to the above analysis, the accelerated corrosion factors considered in this paper mainly included concentration of chloride ion, temperature, 
$\mathrm{pH}$ value and relative humidity. No coupling was considered between the rate of acceleration due to chloride ion and the rate of acceleration due to the $\mathrm{pH}$ value. Also, the effect of the coupling between temperature and humidity on the rate of accelerated corrosion was ignored because salt spray does not condense or sublimate at the considered temperature of $35^{\circ} \mathrm{C}$. Hence the influence of the four factors on the rate of accelerated corrosion was considered independent of each other. Therefore, the total accelerating rate of the accelerated corrosion test was equal to the product of the accelerating rates for the four factors and was obtained as 196.8 times. Given that bridge bearing is required to have a service life of 60 years, the total test duration of the artificial accelerated corrosion test was taken as 2664 hours (111 days, i.e., 60×365/196.8).

Test conditions for the corrosion test of sliding pairs

The vertical load bearing capacity of sliding pairs is insignificantly affected by the accelerated corrosion test because Teflon plate has very low water absorption, strong resistance to high temperature and corrosion resistant properties. Hence, variations in static and dynamic friction coefficient of sliding pairs were studied mainly in the horizontal direction. Two methods were used to perform the accelerated corrosion test of sliding pairs. In the first method, the sliding pairs was taken out and tested after it was continuously corroded for 2664 hours. In the second method, the sliding pairs was taken out and tested at intervals for certain period. In order to determine if the final results were affected by the difference in the two methods, the test conditions were as follows: (i) the continuous-salt-spray test was performed on sliding pairs \#9 \#12, (ii) the periodic-salt-spray test was performed on sliding pairs \#1 \#4 and the pairs were taken out and tested for performance at 222-hourinterval, and (iii) the wet-and-dry-cycle test was performed on sliding pairs \#5 \#8. The change in performance of sliding pairs was simulated for real marine exposure for 5 years, 10 years, 20 years, 30 years, 45 years, and 60 years. The test conditions are given in Table.1. The ratio of the duration of dry exposure to wet exposure was $2: 1$. The temperature was maintained at $35^{\circ} \mathrm{C}$. The period in the salt -spray test was taken as 24 hours (the wetting time was taken as 8 hours and the drying time was taken as 16 hours). The ratio of the duration of dry exposure to wet exposure in each test cycle in the wet-and-dry-cycle test was also 2:1.

Table 1-Periodic-salt-spray test and wet-dry-cyclic test conditions of sliding pairs

\begin{tabular}{|c|c|c|c|c|}
\hline No. & Test conditions & $\begin{array}{c}\text { Test time/h } \\
\text { (i.e. actual usage time /year) }\end{array}$ & Test item & Test objects \\
\hline 1 & Before test & 0 & Static and dynamic friction coefficient & $\# 1 \sim \# 12$ \\
\hline 2 & \multirow{6}{*}{$\begin{array}{l}\text { Cycle-salt-spray test / } \\
\text { Wet-dry-cycling test }\end{array}$} & 222h (5year) & Static and dynamic friction coefficient & $\begin{array}{l}\# 1 \sim \# 4 / \\
\# 5 \sim \# 8\end{array}$ \\
\hline 3 & & 444h (10year) & Static and dynamic friction coefficient & $\begin{array}{l}\# 1 \sim \# 4 / \\
\# 5 \sim \# 8\end{array}$ \\
\hline 4 & & 888h (20year) & Static and dynamic friction coefficient & $\begin{array}{l}\# 1 \sim \# 4 / \\
\# 5 \sim \# 8\end{array}$ \\
\hline 5 & & 1332h (30year) & Static and dynamic friction coefficient & $\begin{array}{l}\# 1 \sim \# 4 / \\
\# 5 \sim \# 8\end{array}$ \\
\hline 6 & & 1998h (45year) & Static and dynamic friction coefficient & $\begin{array}{l}\# 1 \sim \# 4 / \\
\# 5 \sim \# 8\end{array}$ \\
\hline 7 & & 2664h (60year) & Static and dynamic friction coefficient & $\# 1 \sim 12$ \\
\hline
\end{tabular}

\section{Artificial accelerated corrosion test}

Before the artificial accelerated corrosion test, the sliding pairs were tested for the horizontal hysteretic behavior. Then, the sliding pairs and the friction pendulums were simultaneously placed in the salt-spray box and the constant temperature box at $35^{\circ} \mathrm{C}$ to conduct the experiment. The devices used in the test are, respectively, shown in Figs. 3 and 4. 


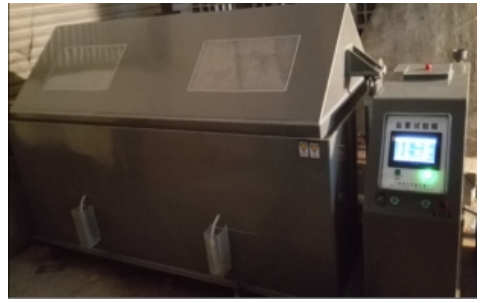

(a)

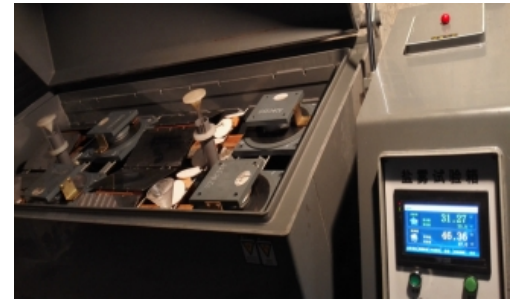

(b)

Fig. 3 Salt spray test chamber and test specimen. (a)Salt spray test chamber. (b)Test specimen

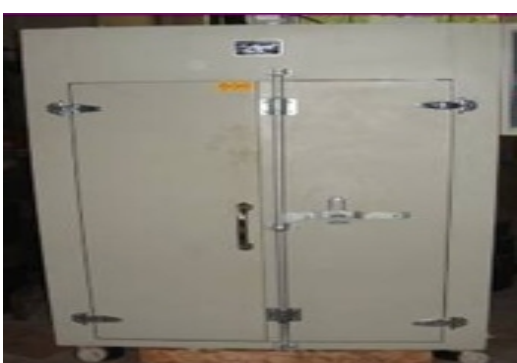

(a)

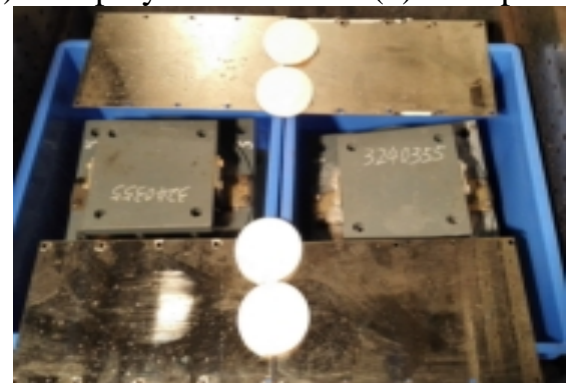

(b)

Fig. 4 Constant temperature test chamber and test pecimen.

(a)Constant-temperature test chamber. (b)Test specimen.

Periodic-salt-spray test

Experimental observation

Fig. 5 shows the experimental phenomena of sliding pairs \#1 \#4 in the periodic-salt-spray corrosion test at the time nodes of 222h (5 years), 444h (10years), 888h (20years), 1332h (30 years), 1998h (45years) and 2664h (60years).

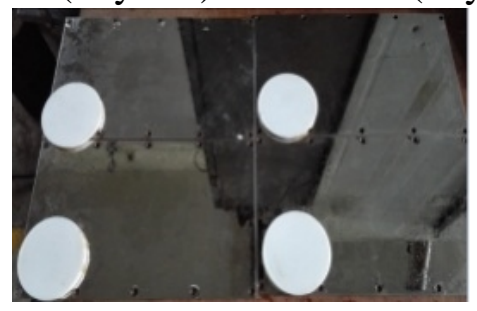

(a)

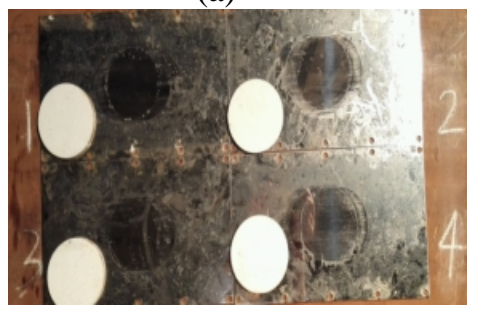

(d)

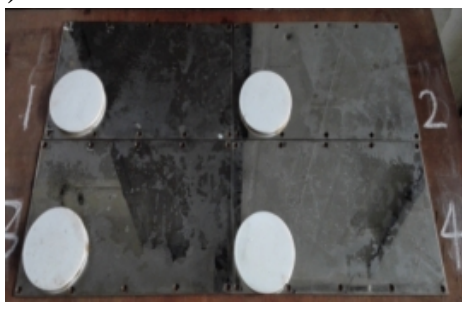

(b)

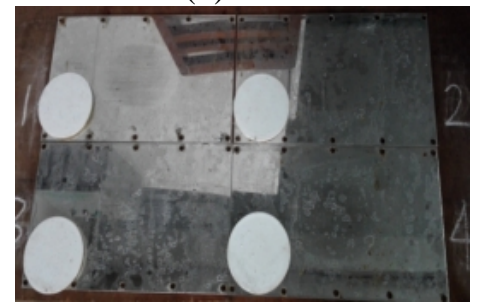

(e)

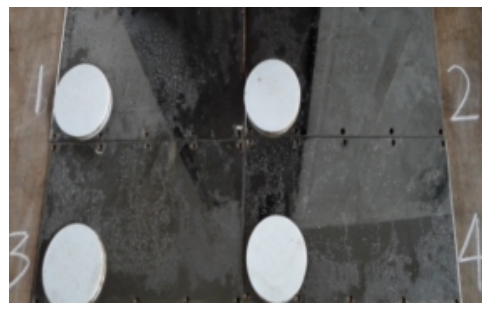

(c)

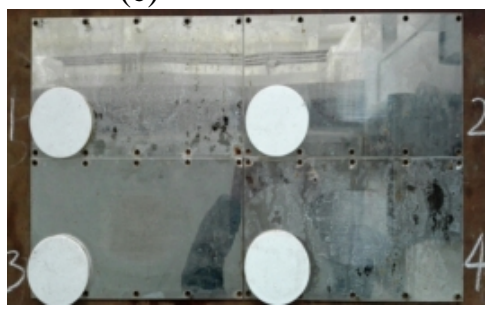

(f)

Fig. 5 Periodic-salt-spray test of sliding pairs \#1 \#4.

(a)After 222h (5years). (b)After 444h (10years). (c)After 888h (20years). (d)After 1332h (30years). (e)After 1998h (45years). (f)After 2664h (60years).

As shown in Fig. 5, with the periodic-salt-spray test, the stainless steel plate was changed from the original completely bright plate free from corrosion to the plate with many white salt crystals on its surface. However, the salt crystals on the stainless steel plate were gradually reduced from $1332 \mathrm{~h}$ to $2664 \mathrm{~h}$. This observation is consistent with the trend of corrosion of steel in seawater, i.e., corrosion is serious in the early stage but after a certain period, the corrosion layer on the surface of steel provides a protective effect on the steel. As the corrosion continues, the protective film is destroyed and the steel is further corroded. In contrast, Teflon plate was almost not changed, in line with its characteristics of high corrosion resistance, superior stability and low water absorption.

The experimental phenomenon of sliding pairs \#9 \#12 (Fig. 6) and of sliding pairs \#1 \#4 (Fig. 5) at 2664h were basically consistent. It shows that the difference in the method of testing the sliding pairs (In the first method, the sliding pairs was taken out and tested after it was continuously 
corroded for 2664 hours. In the second method, the sliding pairs was taken out and tested at intervals for certain period.) has little impact on the ultimate performance of the sliding pairs. The difference between the two groups is, however, mainly reflected in the friction-slip distance of the sliding pairs: the distance in the former case was much smaller than the latter case. This indicates that the wear rates of the two groups of Teflon plates were different Nima et al.'s study [29] showed that the wear rate of the Teflon plate was below 3\% when the friction-slip distance of the plate was below $50 \mathrm{~m}$. The total friction-slip distance of sliding pairs \#1 \#4 was only $2.24 \mathrm{~m}$, so the loss in thickness of the sliding pairs can be neglected. Hence, the main influencing factor can be concluded as the duration of corrosion.

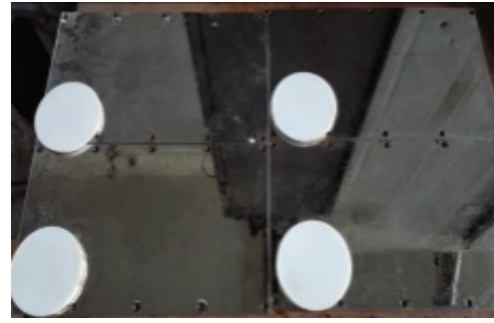

(a)

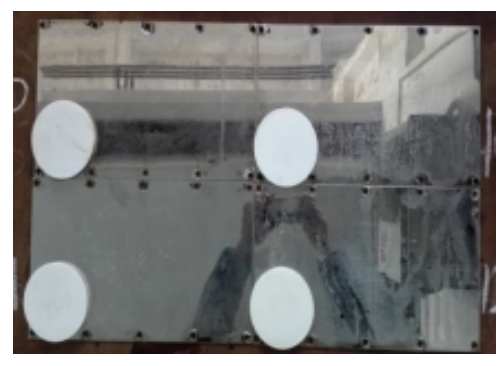

(b)

Fig. 6 Periodic-salt-spray test of sliding pairs \#9 \#12. (a)Before test. (b)After 2664h

Results of performance test

As shown in Fig. 8, mechanical performance test was performed on a large-scale multi-function pull-load-shear test machine with electro-hydraulic servo control (the first in China), which was developed by Earthquake Engineering Research \& Test Center of Guangzhou University. Sine-wave load was input in a displacement control mode. The vertical compressive force on the sliding pairs was 30MPa. The slip velocity, the single side slipping distance and the number of loading cycles were taken as $0.4 \mathrm{~mm} / \mathrm{s}, 20 \mathrm{~mm}$ and 4 , respectively. The horizontal force corresponding to the starting point of the first cycle was used to calculate the initial static friction coefficient. Third cycle was used to finish the calculation of the dynamic friction coefficient. The force-displacement hysteresis curves of sliding pairs \#1 at each corrosion time are shown in Fig. 9. With the change in corrosion time, the hysteresis curve of the sliding pairs was first increased, then decreased, and finally increased.

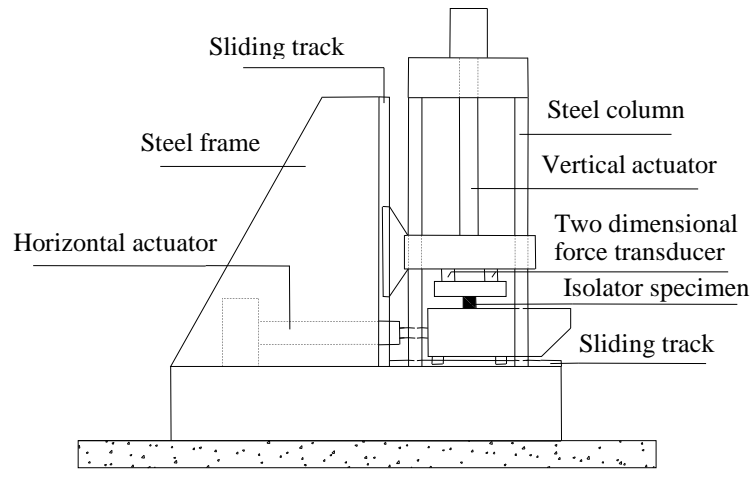

Fig. 7 The tension-shear test set-up

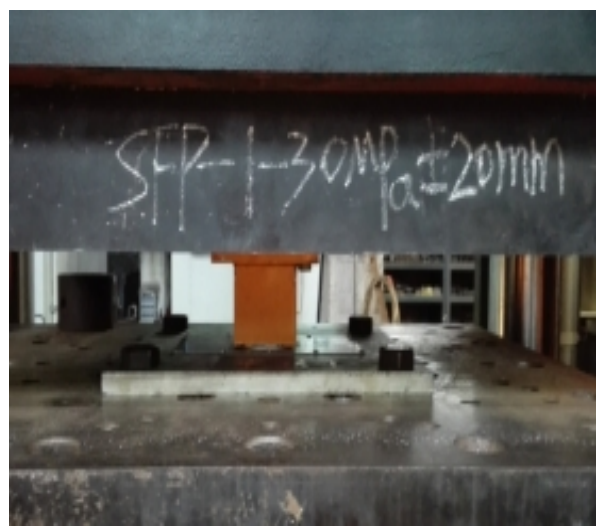

Fig. 8 Horizontal hysteretic performance test 


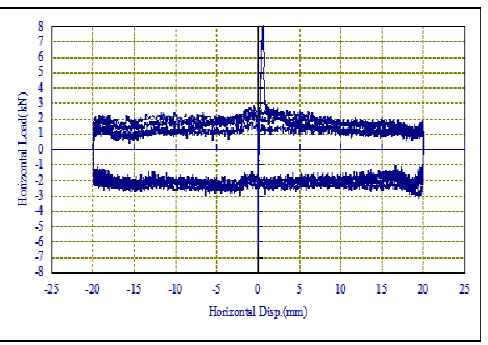

(a)

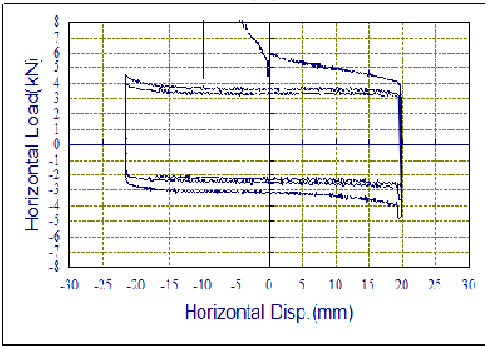

(d)

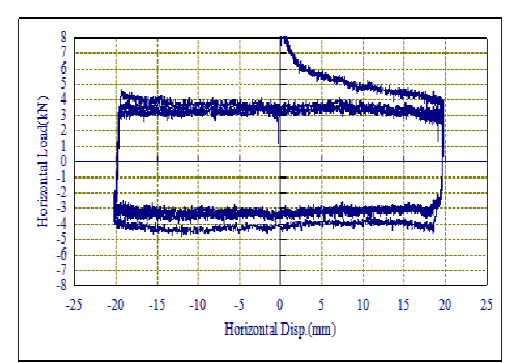

(b)

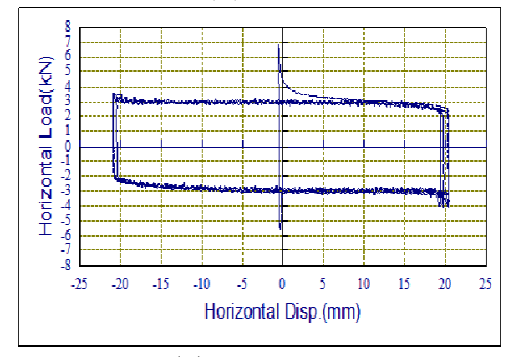

(e)

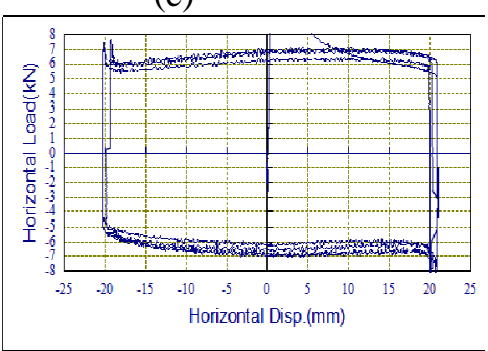

(g)

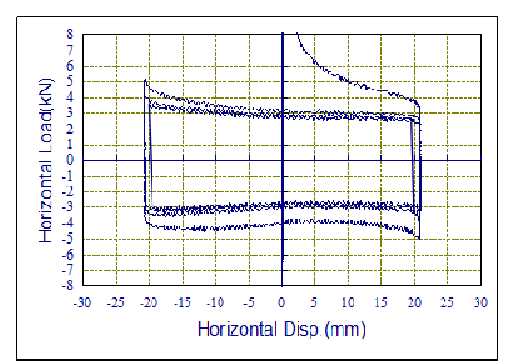

(c)

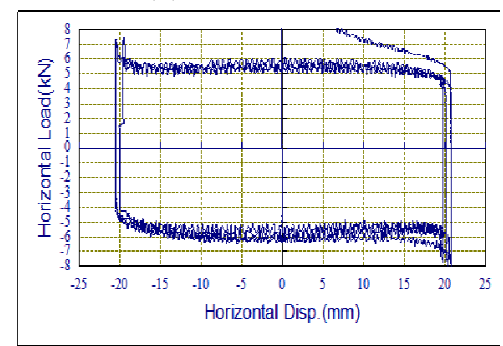

(f)

Fig. 9 Hysteresis curve of sliding pairs \#1 at each corrosion time.

(a)0h. (b) After 222h (5years). (c)After 444h(10years). (d)After 888h (20years).(e)After 1332h

(30years). (f)1998h (45years). (g)After 2664h (60years).

Surface pressure, temperature, slip velocity, times of repeated loading and accumulated slipping distance were kept constant because this paper focused on the variation of friction coefficient with duration of corrosion. While it was easy to make surface pressure, slip velocity, times of repeated loading and accumulated slipping distance constant, the temperature in the test room was not constant as the whole test took a few months to complete. Therefore, the apparent friction coefficient should be normalized to a constant temperature. Previous research [30] has shown that friction coefficient is decreased with an increase in ambient temperature, as shown in Fig. 10. With an increase in ambient temperature, the rate of reduction of friction coefficient is about $0.09 \% /{ }^{\circ} \mathrm{C}$. Therefore, the friction coefficient can be normalized to $20^{\circ} \mathrm{C}$, that is, the average ambient temperature for the actual use of an isolated friction pendulum bearing.

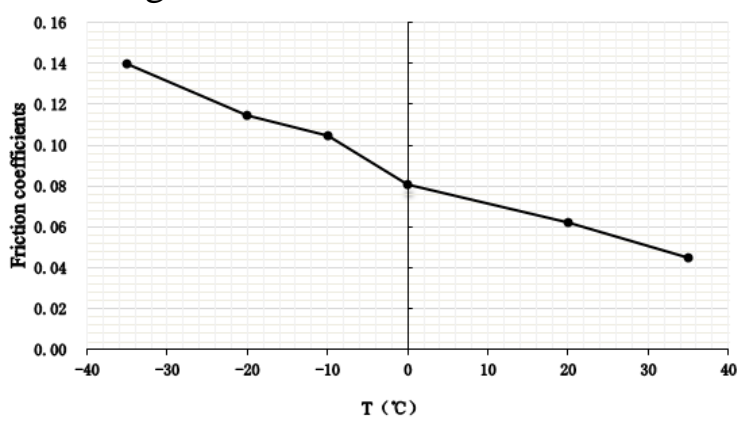

Fig. 10 Influence of ambient temperature on the sliding friction coefficient of a sliding friction material

The dynamic and static friction coefficients of sliding pairs \#1 \#4 at each corrosion time is shown in Fig. 11. With an increase in corrosion time, the static and dynamic friction coefficients of the sliding pairs first slowly increased, then slowly decreased, next increased and finally decreased, showing an obviously sine-wave phenomenon having peaks and valleys. After the corrosion of $2664 \mathrm{~h}$, 
the static friction coefficient was greater than its initial value in general and the dynamic friction coefficient was generally smaller than its initial value.

It should be noted that the static friction coefficient was studied in the test because the horizontal external load should be resisted by the static friction force between stainless steel plate and Teflon plate, and the connecting piece between upper plate and lower plate of the bearing during normal use. Actually, the static friction force ensures the stability of the bearing under a relatively small horizontal force. The static friction coefficient is also related to residual displacement. For instance, after an earthquake, when the static friction coefficient is too large and the restoring force provided by the vertical force is equal to the static friction force on the sliding surface, the bearing cannot be completely restored to its initial position. Accordingly, if the residual displacement of the bearing is too large, the upper structure cannot be returned to the state of normal use.

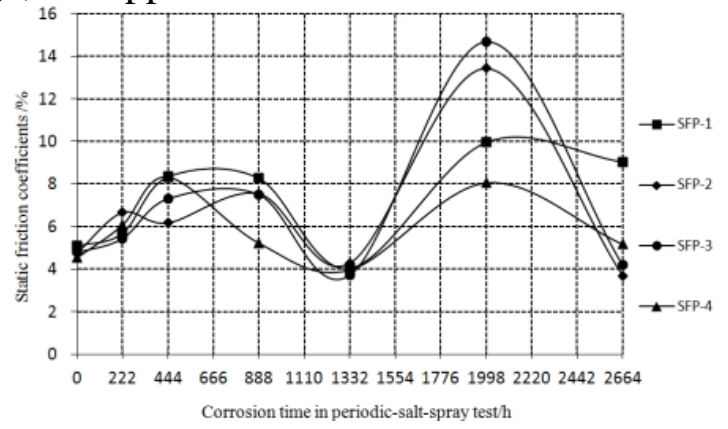

(a)

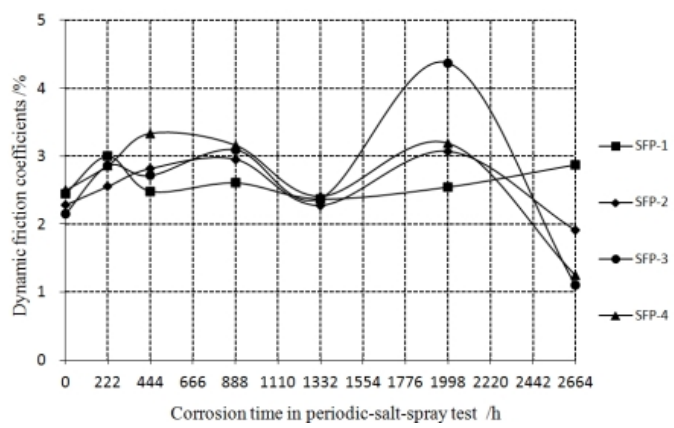

(b)

Fig. 11 The friction coefficients of Sliding pairs \#1 \#4 at each corrosion time.

(a)The change law of static friction coefficient with time. (b)The change law of dynamic friction coefficient with time.

The average values of static and dynamic friction coefficients of \#1 \#4 sliding pairs at each corrosion time were plotted against time and fitted to obtain relationships for the variation in friction coefficient with corrosion time, as shown in Fig. 12.

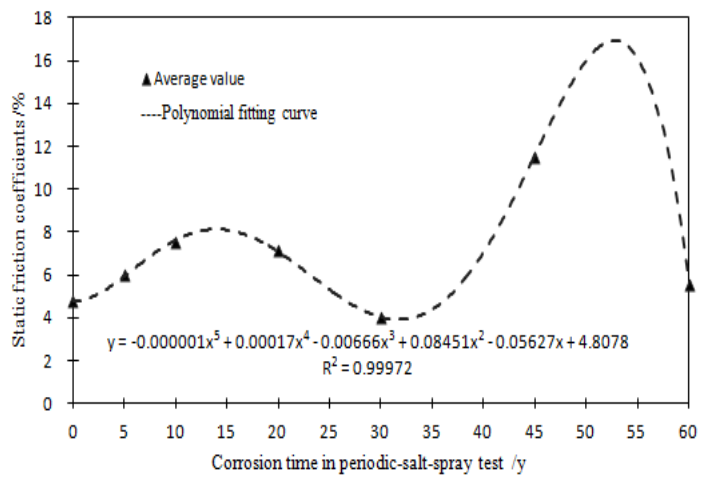

(a)

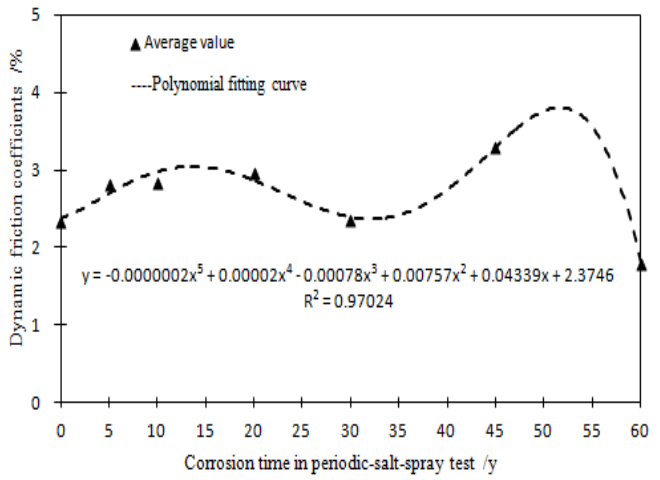

(b)

Fig. 12 The average values of friction coefficients for sliding pairs \#1 \#4 at each corrosion time. (a)The change law of average value of static coefficient with time. (b)The change law of average value of dynamic coefficient with time.

As shown in Fig. 12, the static and dynamic friction coefficients of sliding pairs increased slowly with an increase in corrosion time from 0 to 15 years. Thereafter, the coefficients decreased slowly from 15 to 30 years. The minimum value of the static friction coefficient was smaller than its initial value. The minimum value of the dynamic friction coefficient was generally equal to its initial value. The friction coefficients suddenly increased from 30 to 53 years and suddenly decreased from 53 to 60 years. After 60 years of corrosion, the final value of static friction coefficient was slightly greater than its initial value and the rate of increase was $15.24 \%$. However, the final value of the dynamic friction coefficient was less than its initial value.

The variations in static and dynamic friction coefficients were generally consistent with the test phenomena of the sliding pairs and the trend of deterioration of stainless steel under marine corrosion. This can be explained as follows. Stainless steel plates of the sliding pairs were completely light at 
first. In 0 to 15 years, salt crystals on the surface of stainless steel were gradually accumulated. Pitting corrosion occurred on the surface of the steel plate and the surface was not smooth. Hence, the horizontal force required at the beginning of the slide and the friction coefficients both increased gradually. In 15 to 30 years, the friction coefficients decreased slowly. The stainless steel plate was in a passive state at this stage and its surface was covered by a layer of thin and invisible oxide film formed by the reaction between the metal and the media. The oxide film played a role in inhibiting the dissolution reaction of the metal [31]. The surface of stainless steel was smoother than before due to the oxide film and the friction coefficients were decreased. The reason for the sudden increase in friction coefficients in 30 to 53 years is that the oxide film was destroyed. Consequently, corrosion was more serious and the surface was rougher. The reason for the sudden decrease in friction coefficient in 53 to 60 years is that the oxide film was rebuilt at the stage and was thicker due to the previous damage. Hence, the surface of stainless steel was smoother and the friction coefficients were suddenly decreased.

According to the variation in the average values of dynamic and static friction coefficients for sliding pairs \#1 \#4 with corrosion time, the equations describing the relationship between the two variables is given by Eq. 1 .

$$
\begin{aligned}
& \mu_{s}=-10^{-6} \cdot t^{5}+1.7 \cdot 10^{-4} \cdot t^{4}-6.66 \cdot 10^{-3} \cdot t^{3}+8.451 \cdot 10^{-2} \cdot t^{2}-5.627 \cdot 10^{-2} \cdot t+4.8078 \\
& \mu_{d}=-2 \cdot 10^{-7} \cdot t^{5}+2 \cdot 10^{-5} \cdot t^{4}-7.8 \cdot 10^{-4} \cdot t^{3}+7.57 \cdot 10^{-3} \cdot t^{2}+4.339 \cdot 10^{-2} \cdot t+2.3746
\end{aligned}
$$

where $\mu_{s}$ and $\mu_{d}$ are, respectively, the static friction coefficient and dynamic friction coefficient, measured in percentage; and $t$ is time (year). The correlation coefficients of the equations for $\mu_{s}$ and $\mu_{d}$ were, respectively, 0.99972 and 0.97024 , which shows that the correlations are in good agreement.

\section{Comparison of different test methods}

According to the above mentioned discussion in section 1.2, the continuous-salt-spray test carried out on sliding pairs \#9 \#12 was designed to investigate the effect of the periodic-salt-spray test carried out on sliding pairs \#1 \#4 on the final results. Comparison of the static and dynamic friction coefficients at $0 \mathrm{~h}$ and $2664 \mathrm{~h}$ between sliding pairs \#1 \#4 and \#9 \#12 is shown in Table 2.

Table 2 Comparison of the static and dynamic friction coefficients between \#1 \#4 and \#9 \#12 sliding pairs

\begin{tabular}{ccccc}
\hline sliding pairs & & $\# 1 \sim \# 4$ & $\# 9 \sim \# 12$ & Variation tendency \\
\hline \multirow{2}{*}{ Static friction coefficients } & $0 \mathrm{~h}$ & 0.0479 & 0.0539 & Increase \\
& $2664 \mathrm{~h}$ & 0.0552 & 0.0597 & Increase \\
\hline \multirow{2}{*}{ Dynamic friction coefficients } & $0 \mathrm{~h}$ & 0.0234 & 0.0231 & Decrease \\
& $2664 \mathrm{~h}$ & 0.0178 & 0.0167 & Decrease \\
\hline
\end{tabular}

As shown in Table 2, after $2664 \mathrm{~h}$ (60 years) of periodic-salt-spray corrosion, the ultimate static friction coefficients for sliding pairs \#1 \#4 and \#9 \#12 were both greater than the corresponding initial values by $15.24 \%$ and $10.76 \%$, respectively. The final dynamic friction coefficients for sliding pairs \#1 \#4 and \#9 \#12 were both smaller than the corresponding initial values by $23.93 \%$ and $27.71 \%$, respectively. The initial and final static friction coefficients for sliding pairs \#9 \#12 were both greater than the values for sliding pairs \#1 \#4. The initial and final dynamic friction coefficients for sliding pairs \#9 \#12 were both smaller than the values for sliding pairs \#1 \#4. The increase in the static friction coefficients and the decrease in the dynamic friction coefficients varied by $<5 \%$ when compared between sliding pairs \#1 \#4 and \#9 \#12. Therefore, the final value of the corrosion of stainless steel was insignificantly affected by the test method in which the sliding pairs was taken out and tested at intervals for a certain period. 
Wet-and-dry-cycle corrosion test

Experimental phenomena

Fig. 13 shows the experimental phenomena of sliding pairs \#5 \#8 under the wet-and-dry-cycle corrosion at time nodes 222h(5years), 444h(10years), 888h(20years), 1332h(30years), 1998h(45years) and 2664h(60years).

As shown in Fig. 13, the corrosion phenomena of sliding pairs in wet-and-dry-cycle test were similar to those in the periodic-salt-spray test. The cyclic corrosion process that occurred on the surface of stainless steel included slight corrosion, severe corrosion, formation of a passive film, destruction of the passive film, and further corrosion and regeneration of the passive film. Compared to the periodic-salt-spray test, salt crystals on the surface of the stainless steel plate in the wet-and-dry-cycle test at each time node were markedly greater in number and the surface of the stainless steel plate in the wet-and-dry-cycle test was rougher.

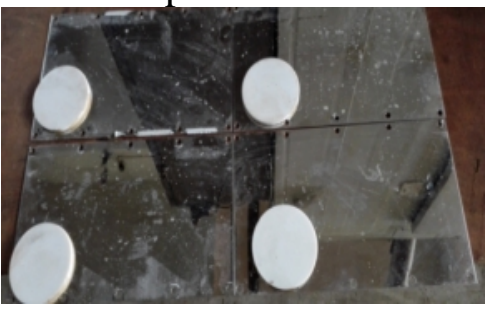

(a)

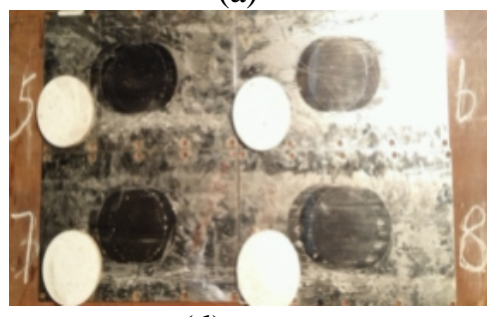

(d)

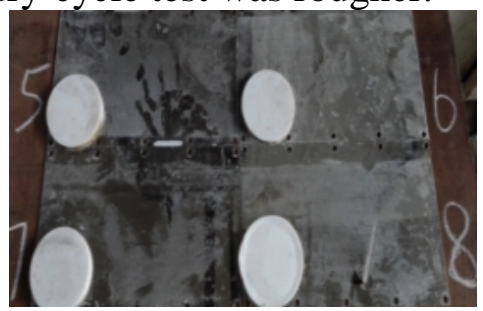

(b)

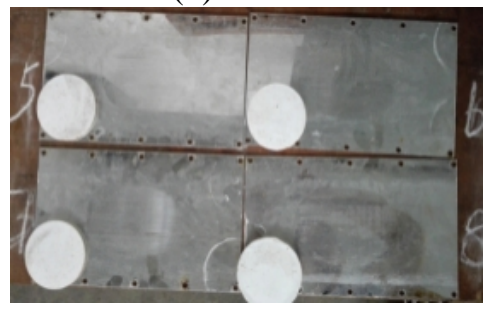

(e)

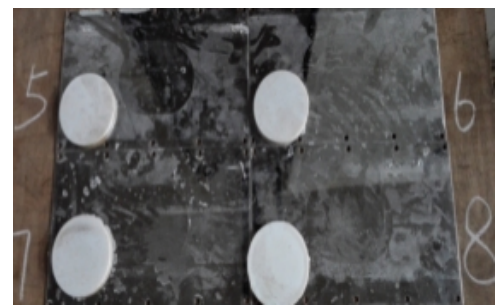

(c)

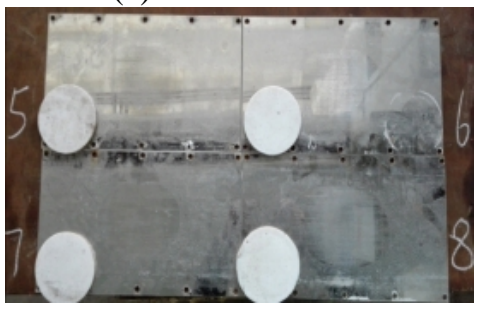

(f)

Fig. 13 Wet-dry-cycling test of Sliding pairs \#5 \#8.

(a)After 222h. (b)After 444h. (c)After 888h. (d)After 1332h. (e)After 1998h. (f)After 2664h.

\section{Performance test}

Fig. 14 shows the static and dynamic friction coefficients of sliding pairs \#5 \#8 at each time node in the wet-and-dry-cycle test. The average values of the static and dynamic friction coefficients of sliding pairs \#5 \#8 in the wet-and-dry-cycle test are shown in Fig. 15.

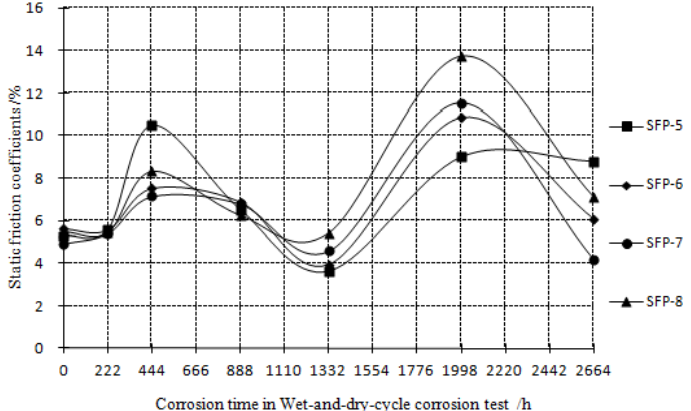

(a)

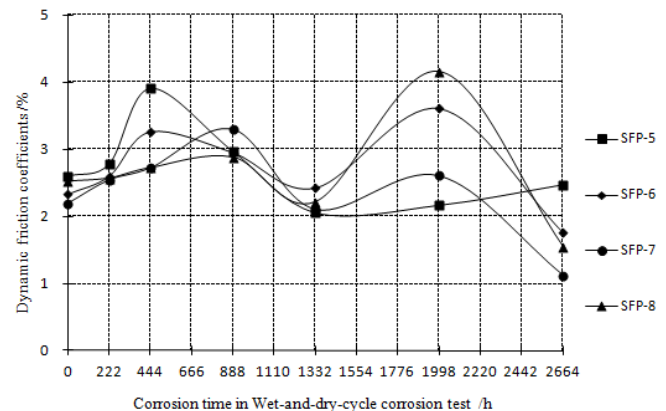

(b)

Fig. 14 The friction coefficients of sliding Pairs \#5 \#8 in the wet-dry-cycling test.

(a)The change law of static friction coefficient with time. (b)The change law of dynamic friction coefficient with time. 


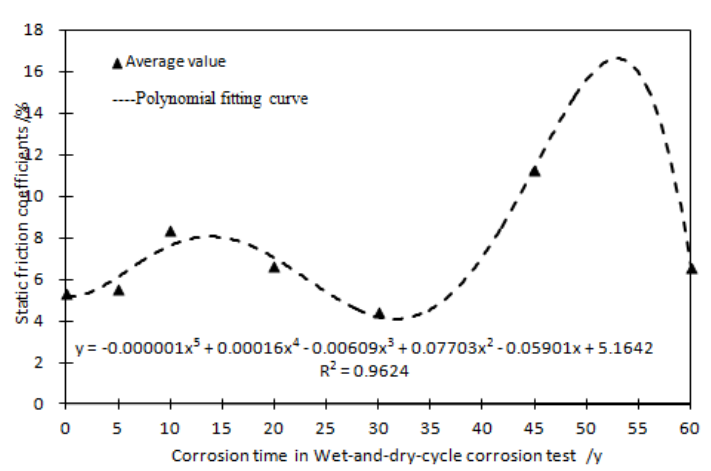

(a)

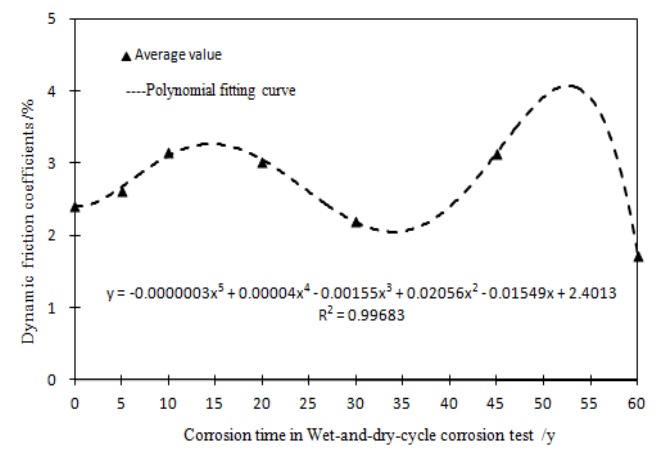

(b)

Fig. 15 The average values of Friction coefficients of sliding pairs \#5 \#8 at each corrosion time.

(a)The change law of average value of static coefficient with time. (b)The change law of average value of dynamic coefficient with time.

As shown in Figs. 14 and 15, the variations in the static and dynamic friction coefficients of the sliding pairs in the wet-and-dry-cycle corrosion test was basically consistent with that in the periodic-salt-spray corrosion test (Figs. 10 and 11). The coefficients increased slowly from 0 to 15 years, decreased slowly from 15 to 30 years, increased suddenly from 30 to 53 years and decreased suddenly from 53 to 60 years. After 2664h (60 years) of the wet-and-dry-cycle corrosion, the ultimate static friction coefficient was greater than its initial value by $22.51 \%$. The ultimate dynamic friction coefficient was smaller than its initial value by $28.63 \%$.

According to the variation in the average values of the dynamic and static friction coefficients for sliding pairs \#5 \#8 with corrosion time, the equations describing the relationship between the two variables are given by Eq. 2 .

$$
\begin{aligned}
& \mu_{s}=-10^{-6} \cdot t^{5}+1.6 \cdot 10^{-4} \cdot t^{4}-6.09 \cdot 10^{-3} \cdot t^{3}+7.703 \cdot 10^{-2} \cdot t^{2}-5.901 \cdot 10^{-2} \cdot t+5.1642 \\
& \mu_{d}=-3 \cdot 10^{-7} \cdot t^{5}+4 \cdot 10^{-5} \cdot t^{4}-1.55 \cdot 10^{-3} \cdot t^{3}+2.056 \cdot 10^{-2} \cdot t^{2}-1.549 \cdot 10^{-2} \cdot t+2.4013
\end{aligned}
$$

where $\mu_{s}$ and $\mu_{d}$ are, respectively, the static friction coefficient and dynamic friction coefficient, in percentage; and t is time in year. The correlation coefficients for $\mu_{s}$ and $\mu_{d}$ were respectively 0.9624 and 0.99683 , which shows that the correlations are in good agreement.

Comparison of periodic-salt-spray corrosion test and wet-and-dry-cycle corrosion test

Comparison of friction coefficients in the periodic-salt-spray corrosion test and in wet-and-dry-cycle corrosion test is shown in Fig. 16. The variation in the static friction coefficients at each node of corrosion time obtained by two kinds of corrosion test was basically consistent with each other. The two trend lines were almost coincident and both increased slowly at first, then decreased slowly, next increased suddenly and finally decreased suddenly. The variation in the dynamic friction coefficients at each corrosion time node obtained by two kinds of corrosion test was generally consistent with each other. Even though the trend lines did not completely overlap, the coincidence rate was very high. After 60 years of real marine environment corrosion, the final dynamic friction coefficient was smaller than its initial value. The corrosion time at peaks and troughs in the curve describing the relationship between the static friction coefficients and corrosion time was consistent with that in the curve describing the relationship between the dynamic friction coefficients and corrosion time. 


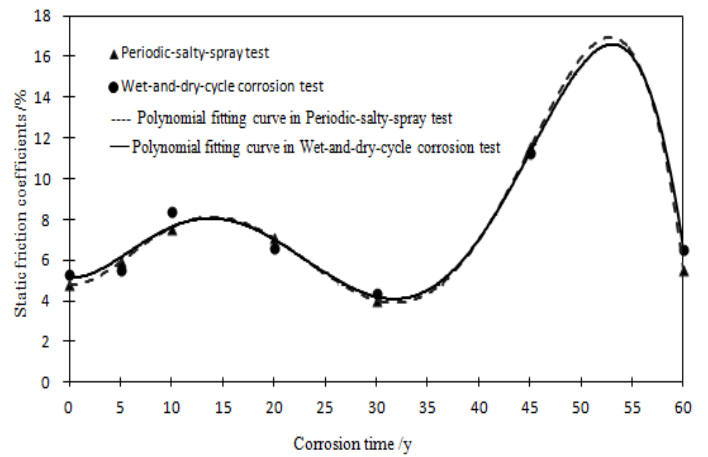

(a)

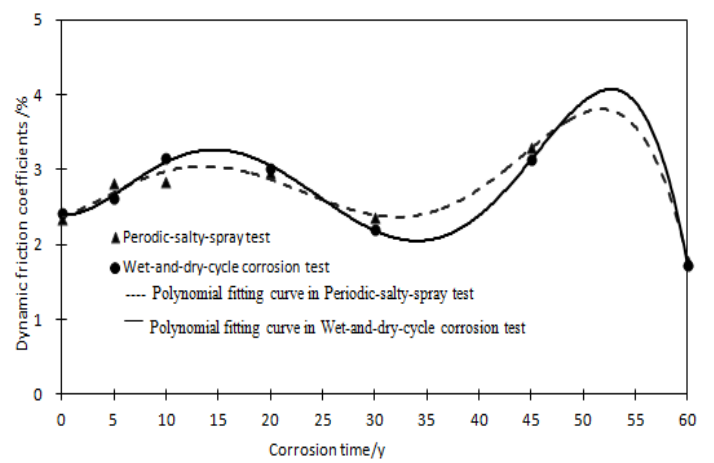

(b)

Fig. 16 Comparison of average variations in the static and Dynamic friction coefficients of the sliding pairs material. (a)Comparison of average variation in static friction coefficient. (b)Comparison of average variation in the dynamic friction coefficient.

\section{Conclusions}

In this paper, periodic-salt-spray accelerated corrosion test and wet-and-dry-cycle accelerated corrosion test were performed on sliding pairs, that were used to simulate the situations of bearings in bridges exposed to marine environment in splash zone and atmospheric zone. The macroscopic phenomena of corrosion in the sliding pairs in each corrosion time were analyzed. Relationships were obtained for the variations in the static and dynamic friction coefficients with corrosion time. The main conclusions are as follows:

1. Between the two tests, the variations in the friction coefficients of sliding pairs in the splash zone and atmospheric zone with corrosion time were consistent, both showing periodic sine curve. The curves showed a trend that increased at first, then decreased, next increased and finally decreased. It shows that the corrosion of the sliding pair exposed to marine environment is a periodic and changing process. The energy dissipation capacity of the bearing during the life span of a bridge is likely to fluctuate.

2. After 60 years of marine environment corrosion, the ultimate static friction coefficient of sliding pairs was greater than its initial value and the final dynamic friction coefficient was smaller than its initial value. It shows that when the service life of a bridge is expired, it is more difficult to overcome the static friction force and to cause the bearing to slip. Consequently, the energy dissipation capacity of the bearing is reduced.

3. According to the comparison of the corrosion phenomena and the trend of variation between \#1 \#4 and \#9 \#12 sliding pairs, in the salt-spray test, the final test results were insignificantly affected by the test method in which the sliding pairs was taken out and tested at intervals for a certain period.

4. For all the fitting curves describing the variation in the static and dynamic friction coefficients with corrosion time, the correlation coefficients were always greater than 0.95 , thus ensuring good correlations.

\section{Acknowledgments}

The research described in this paper was financially supported by: National Natural Science Foundation of China under Grant Nos. 51578170 and 51678173, Program for Changjiang Scholars and Innovative Research Team in University (IRT13057), Science and Technology Program of Guangzhou, China (1201421152 and 201707010295), the Natural Science Foundation of Guangdong Province, China (2017A030313298). 


\section{References}

[1] Han Qiang, Liu Wenguang, Du Xiu-li et al. China Journal of Highway and Transport, 25(5) (2012), p.82-88.

[2] Yang Lin, Chang Yongping, Zhou Xiyuan et al. Journal of Building Structures, 29(4) (2008), p.65-72.

[3] Tsaia C.S., Po-Ching Lub, Wen-Shin Chenb, et al. Engineering Structures, 30 (2008), p.2321-2329.

[4] Murat Eroz, Reginald DesRoches. Engineering Structures, 56(2013), p.585-599.

[5] Yenpo Wang, Laplo Chung, Weihsin Liao. Earthquake Engineering and Structural Dynamics, 27 (1998), p.1069-1093.

[6] Jangid R S. Journal of Bridge Engineering,13 (2008), p.319-330.

[7] Xia Jun, Wang Xuejun, Wang Weidong. China Plastics Industry, 42(4) (2014), p.124-130.

[8] Wang Yuanqing, Yuan Huanxin, Shi Yongjiu et al. Steel Construction, 25(2) (2010), p.1-13.

[9] Wang Shaoyan, Cui Yunhai. Journal of Shenyang Normal University ( Natural Science), 23(2) (2005), p.158-160.

[10] Zhu Xiangrong, Huang Guiqiao, Lin Leyun et al. Journal of Chinese Society for Corrosion and Protection, 25(3) (2005), p.142-148.

[11] You Jiantao, Huang Guiqiao, Wang Xiangrun. Corrosion Science and Protection Technology, 13(R) (2001), p.437-450.

[12] Liang Caifeng Yu Chunjuan Hou Wentai. Journal of Chinese Society for Corrosion and Protection, 19(4) (1999), p.227-232.

[13] Fan Guangwei, Qin Liyan, Liu Jie. Journal of North University of China (Natural Science Edition), 28(3) (2007), p.272-278.

[14] Su Lulu. Master Dissertation, Shandong University, Jinan.(2010)

[15] Pan Xudong, Wang Xiangming. Industrial Water Treatment, 33(3) (2013), p.14-17.

[16] Atashin S., Pakshir M., Yazdani A. Materials and Design, 32(2011), p.1315-1324.

[17] Lothongkum G., Wongpanya P., Morito. S. Corrosion Science, 48 (2006), p.137-153.

[18] Ali Soleimani Dorcheh, RickN.Durham, MathiasC.Galetz. Solar Energy Materials \& Solar Cells, 144(2016), p.109-116.

[19] Cai Baoping, Liu Yonghong, Tian Xiaojie, et al. Corrosion Science, 52 (2010), p.3235-3242.

[20] Dolce, M., Cardone, D., \& Croatto, F. Bulletin of Earthquake Engineering, 3 (2005), p.75-99.

[21] Xia Lanting, Wang Lucai, Huang Guiqiao. China Foundry Machinery \& Technology, 6 (2002), p.1-4.

[22] Luo Hong, Li Xiaogang, Dong Chaofang et al. Journal of Chinese Society for Corrosion and Protection, 33(3) (2013), p.193-198.

[23] Zhang Qiang, Xiong Anyuan, Zhang Jinyan et al. Journal of Applied Meteorological Science, 20(6) (2009), p.692-698.

[24] Jiao Rangjie. Journal of Beijing Forestry University, 9(4) (1987), p.413-416.

[25] Hou Baorong. Science and Management, 5 (2004), p.7-8. 
[26] Deng Feifeng, Pei Feng, Liu Yongjun. Central China Electric Power, 21(2) (2008), p.57-61.

[27] Yangxiang, Fei Hengtao, Li Ziyang et al. Science and Technology Information, 27 (2014), p.235-236.

[28] Cao Dingguo, Ren Sanyuan, Wang Haowei. Acta Aeronautica ET Astronautica Sinica, 29(3) (2008), p.634-639.

[29] Nima Ala, Edward H, Atorod Azizinamini. Journal of Bridge Engineering, 21(2) (2016), p.1-11.

[30] Quaglini V., Dubini P., Poggi C. Bulliten of Earthquake Engineering, 10 (2012), p.717-740.

[31] Wang Shutian. Inner Mongolia Petrochemical Technology, (22) (2009), p.85-86. 